\title{
Carcass characteristics and meat quality of lambs that are fed diets with palm kernel cake
}

\author{
Rozilda da Conceição dos Santos ${ }^{1}$, Daiany Iris Gomes ${ }^{1, *}$, Kaliandra Souza Alves ${ }^{1}$, Rafael Mezzomo ${ }^{1}$, \\ Luis Rennan Sampaio Oliveira', Darley Oliveira Cutrim', Samara Bianca Moraes Sacramento', \\ Elizanne de Moura Lima', and Francisco Fernando Ramos de Carvalho
}

\begin{abstract}
* Corresponding Author: Daiany Iris Gomes Tel: +55-94-99221-5041, Fax: +55-94-3346-0221, E-mail: daiany.i.gomes@gmail.com
\end{abstract}

'Department of Animal Science, Federal Rural University of Amazon, Parauapebas, PA 68515-000, Brazil

2 Department of Animal Science, Federal Rural University of Pernambuco, Recife, 52171-900, Brazil

Submitted May 31, 2016; Revised Sept 12, 2016; Accepted Nov 9, 2016
Objective: The aim was to evaluate carcass characteristics, cut yield, and meat quality in lambs that were fed different inclusion levels of palm kernel cake.

Methods: Forty-five woolless castrated male Santa Inês crossbred sheep with an initial average body weight of $23.16 \pm 0.35 \mathrm{~kg}$ were used. The experimental design was a completely randomized design with five treatments, with palm kernel cake in the proportions of $0.0 \%, 7.5 \%, 15.0 \%$, $22.5 \%$, and $30.0 \%$ with nine replications per treatment. After slaughter, the gastrointestinal tract was weighed when it was full, after which it was then emptied. The heart, liver, kidney, pancreas perirenal fat were also collected and weighed. The carcass was split into two identical longitudinal halves and weighed to determine the quantitative and qualitative characteristics.

Results: The empty body weight, carcass weight and yield, and fat thickness decreased linearly $(p<0.05)$ as a function of palm kernel inclusion in the diet. There was no difference $(p>0.05)$ for the rib eye area of animals that were fed palm kernel cake. There was a reduction in the commercial cut weight $(\mathrm{p}<0.05)$, except for the neck weight. The weights of the heart, liver, kidney fat, small, and large intestine, and gastrointestinal tract decreased. Nevertheless, the gastrointestinal content was greater for animals that were fed increasing levels of cake. For the other organs and viscera, differences were not verified $(\mathrm{p}>0.05)$. The sarcomere length decreased linearly $(p<0.05)$, although an effect of the inclusion of palm kernel cake was not observed in other meat quality variables. It is worth noting that the red staining intensity, indicated as A, had a tendency to decrease $(\mathrm{p}=0.050)$.

Conclusion: The inclusion of palm kernel cake up to $30 \%$ in the diet does not lead to changes in meat quality characteristics, except for sarcomere length. Nevertheless, carcass quantitative characteristics decrease with the use of palm kernel cake.

Keywords: Ovine; Meat; Lamb; Palm Kernel Cake

\section{INTRODUCTION}

For farmers that raise sheep, meat is the main commercial product, especially in the north and northeast of Brazil, where the population cultural habits typically involve consumption of plates with lamb meat [1]. In this way, sheep farming has been highlighted as a potential activity for two primordial reasons: first, from an economic point of view, smaller territorial spaces are needed to feed and produce these animals [2] and second, from a nutritional point of view, lamb meat, among other characteristics such as having a high linolenic acid concentration, is more digestible when compared to other ruminants, because the amino acid profile of myofibrillar protein ovine ensures its greater digestibility, which is approximately $99 \%$, while bovine serum albumin has a digestibility of amino acids of $93 \%$ and so it has been attractive to people worried about their health $[3,4]$. 
The use of feedlots generate positive results by reducing slaughter time of the animals; however, the higher feeding costs can become expensive, so studies have been performed while using byproducts as a replacement for standard feedstuffs such as corn and soybean meal in order to reduce costs and at the same time, to guarantee the commercial carcass quality [5]. Among biodiesel byproducts, palm kernel cake represents a promising alternative to concentrate in the diets of lambs because it contains approximately $15 \%$ crude protein and $10 \%$ ether extract [6], which therefore makes it a viable candidate. In studies that have already been conducted, researchers verified the replacement data of elephant grass up to levels of $80 \%$ by palm kernel cake, where dry matter intake decreased from the level of $40 \%$ of replacement [7]. Also, it was verified that the replacement of $34 \%$ of concentrate with palm kernel cake for dairy heifers led to a reduction in the dry matter intake up to $39 \%$ with the maximum level of replacement [8]. In this context, it becomes important to evaluate the quantitative and qualitative carcass characteristics because if they are not guaranteed, farmers may be penalized when the meat is commercialized.

It was evaluated the replacement of $80 \%$ of concentrate with palm kernel cake and found that it resulted in a lower carcass yield, but a greater fat content in the Longisimus dorsi muscle of goats [9]. Therefore, the hypothesis of this study was that moderate inclusion levels of palm kernel cake (up to $30 \%$ of replacement in the diet) could lead to satisfactory results in terms of carcass characteristics and meat quality. Thus, the aim of this study was to evaluate the effects of the replacement of concentrate with palm kernel cake in the proportion of $0.0 \%, 7.5 \%, 15.0 \%, 22.5 \%$, and $30.0 \%$ on the carcass characteristics, cut yield, and meat quality of lambs.

\section{MATERIALS AND METHODS}

\section{Animals, diets and experimental design}

The experiment was conducted in the sheep section at the Federal Rural University of Amazon, Brazil. All procedures and handling of the animals followed the Ethical Principles on Animal Experimentation approved by the Ethics Comission on Animal Use - CEUA/UFRA, under the protocol no 0507/ 2013-17.

Fourty-five woolless castrated male Santa Inês crossbred sheep with an initial average body weight of $23.16 \pm 0.35 \mathrm{~kg}$ and an initial average age of four months were used. The animals were taken to a feedlot, weighed, identified, and then they were adapted to the experimental diet and the feedlot facilities for 20 days. The experiment lasted for 88 days. The experimental design was a completely randomized design with five treatments that corresponded to five levels of replacement of concentrate with palm kernel cake in the proportion of $0.0 \%, 7.5 \%, 15.0 \%, 22.5 \%$, and $30.0 \%$ with nine replications per treatment (Table 1). The diets were formulated in the roughage:concentrate ratio of 50:50 to meet the average daily gain requirements of $200 \mathrm{~g} / \mathrm{animal} / \mathrm{d}$ [10].
Table 1. Ingredients and chemical composition of the experimental diets

\begin{tabular}{lccccc}
\hline \multirow{2}{*}{$\begin{array}{l}\text { Ingredients composition } \\
\text { (g/kg of DM) }\end{array}$} & \multicolumn{5}{c}{ Proportion of kernel cake (\% DM) } \\
\cline { 2 - 6 } & $\mathbf{0}$ & $\mathbf{7 . 5}$ & $\mathbf{1 5}$ & $\mathbf{2 2 . 5}$ & $\mathbf{3 0}$ \\
\hline Elephant silage & 500 & 500 & 500 & 500 & 500 \\
Palm kernel cake & - & 75.0 & 150 & 225 & 300 \\
Corn meal & 245 & 196 & 147 & 98.0 & 44.0 \\
Soybean meal & 240 & 210 & 180 & 150 & 126 \\
Urea & 3.0 & 6.0 & 9.0 & 12.0 & 14.0 \\
Mineral mixture & 10.0 & 10.0 & 10.0 & 10.0 & 10.0 \\
Limestone calcitic & 2.0 & 3.0 & 4.0 & 5.0 & 6.0 \\
Chemical composition (g/kg of DM) & & & & \\
$\quad$ Dry matter & 556 & 563 & 567 & 571 & 574 \\
Organic matter & 928 & 928 & 926 & 925 & 923 \\
Crude protein & 170 & 168 & 167 & 165 & 163 \\
Ether extract & 28.5 & 33.1 & 37.8 & 42.5 & 47.0 \\
$\quad$ Neutral detergent fibreap & 416 & 453 & 489 & 525 & 562 \\
$\quad$ Acid detergent fibre & 290 & 316 & 343 & 370 & 397 \\
Lignin & 47.2 & 54.2 & 61.2 & 68.2 & 75.3 \\
$\quad$ Non-fibrous carbohydrates & 322 & 281 & 248 & 215 & 182 \\
\hline
\end{tabular}

DM, dry matter; ap, corrected for ash and nitrogenous compounds.

Elephant grass silage (Pennisetum purpureum Schum. cv. Napier) was utilized with 75 days of regrowth and were collected to perform the surface silage process. The concentrate was composed of soybean meal, corn meal, palm kernel cake, urea, mineral mix, and limestone (Table 1). The diets were provided twice a day at $0900 \mathrm{~h}$ and $1600 \mathrm{~h}$, as a total mixed ration.

\section{Slaughter, carcass trait data collection and sampling procedures}

Before slaughter, the animals underwent an 18 hour solids fasting period. They were slaughtered by cerebral concussion followed by jugular and carotid venesection. Pre-harvest handling was in accordance with good animal welfare practices, and slaughtering procedures followed the Sanitary and Industrial Inspection Regulation for Animal Origin Products [11]. After slaughter, the gastrointestinal tract (rumen/reticulum, omasum, abomasum, and small and large intestines) was weighed when it was full, after which it was then emptied, washed, and weighed again to determine the empty body weight (EBW). The heart, liver, kidney, pancreas perirenal fat were also collected and weighed.

The carcass was split into two identical longitudinal halves and weighed to determine the hot carcass weight (HCW). All carcasses were refrigerated at $4^{\circ} \mathrm{C}$ for $24 \mathrm{~h}$ and then taken from the cooling chambers and weighed again in order to determine the cold carcass weight (CCW). The difference between the chilled carcass weight and HCW was used to calculate carcass shrink loss. Carcass yield was calculated using HCW and CCW divided by EBW and shrunk body weight and then multiplying the result by 100 . After $24 \mathrm{~h}$ postmortem chills, 12 th rib fat thickness (RFT) and 12th rib longissimus muscle area (LMA) were measured on the left side of each carcass. LMA was traced on transparencies and measured later with a planimeter and RFT measurements 
were taken $3 / 4$ the length ventrally over the longissimus muscle by using a digital paquimeter [12]. In the right half of each carcass commercial cut yield was measured by separating the carcass half into neck, shoulder, rib, loin, leg, and flank steak which were individually.

Longissimus muscle was completely removed from the left side of each carcass and standardized into three $2.54 \mathrm{~cm}$ thick steak samples for the Warner-Bratzler shear force [13]. Sarcomere length, steak thawing, cooking loss, total collagen, collagen solubility, and colorimetric were measured in the same steak samples used for Warner-Bratzler shear force (WBSF) evaluation.

\section{Meat quality analysis}

The WBSF steaks were thawed at $4^{\circ} \mathrm{C}$ for a period of $24 \mathrm{~h}$ and oven broiled in an electric oven pre-heated to $150^{\circ} \mathrm{C}$. Internal steak temperature was monitored with 20-guage copper-constantan thermocouples (Omega Engineering, Stamford, CT, USA) placed in the approximate geometric center of each steak and attached to a digital monitor. When internal steak temperature reached $35^{\circ} \mathrm{C}$, it was turned over and allowed to reach an internal temperature of $70^{\circ} \mathrm{C}$ before removal from the oven. Cooked WBSF steaks were cooled for $24 \mathrm{~h}$ at $4^{\circ} \mathrm{C}$. Two round cores $(1.27$ $\mathrm{cm}$ diameter) were removed from each steak, with six round cores for each animal (three $2.54 \mathrm{~cm}$ thick steaks per animal and two round cores per steak), parallel to the long axis of the muscle fibers [13]. Each core was sheared once through the center, perpendicular to the fiber direction by a Warner-Bratzler shear machine (G-R Manufacturing Company, Manhattan, KS, USA). The sarcomere length was assessed laser diffraction technique [14].

Steak thawing and cooking loss were evaluated on steaks also used for WBSF measurement. For thawing loss evaluation, each steak was weighed frozen and after a period of $24 \mathrm{~h}$ thawing at $4^{\circ} \mathrm{C}$. The cooking loss of each steak was recorded after steaks were oven-broiled during the WBSF processing. Cooking loss was calculated as the difference between the weight of the steaks before and after oven-broiling. Colorimetry was assessed using a colorimeter (CR-310, 50-mm diameter orifice, $10^{\circ}$ standard observer, $\mathrm{D}^{65}$ light source; Minolta Company, Ramsey, NJ, USA) measuring the luminosity $\left(\mathrm{L}^{*}\right)$ and color intensities red $\left(\mathrm{a}^{\star}\right)$ and yellow $\left(\mathrm{b}^{*}\right)$ of Longissimus dorsi muscle [15]. Collagen and its fractions were quantified using the amino acid hydroxyproline technique. A $1 \mathrm{~cm}$ thick steak was homogenized using an industrial blender to quantify the total and soluble collagen. The values of total and soluble collagen were calculated as the following equations:

$\%$ Total collagen $=\%$ Collagen in the sediment $+\%$ Collagen in the supernatant

\author{
Collagen solubility (\%) \\ $=\%$ Collagen in the supernatant $\times 100 / \%$ Total collagen
}

\begin{abstract}
Statistical analysis
The regression analysis of the variables was performed as a function of the inclusion of palm kernel cake in the experimental diets. The linear and quadratic models were tested for model significance $(\mathrm{p}<0.05)$ and biological specificity of each studied variable. All statistical analyses were conducted using Statistical Analysis System (SAS Inst. Inc., Cary, NC, USA) software.
\end{abstract}

\section{RESULTS}

There was a decreasing linear effect $(\mathrm{p}<0.05$; Table 2$)$ in relation to the EBW of animals as a function of the level of inclusion of palm kernel cake. The EBW estimated varied from 25.17 to 20.84 $\mathrm{kg}$. The variables related to carcass weight and yield also decreased linearly $(\mathrm{p}<0.05)$. The subcutaneous fat thickness of animals that were fed palm kernel cake-based diets was lower $(p<0.05)$ than that of animals that were fed diets without palm kernel cake. The subcutaneous fat thickness estimated varied from 2.40 to 1.77 $\mathrm{mm}$. A difference was not verified $(\mathrm{p}>0.05)$ for the rib eye area of animals that were fed palm kernel cake, with an average of $13.54 \mathrm{~cm}^{2}$ (Table 2).

A reduction in the commercial cut weight was observed for animals that were fed palm kernel cake with a decreasing linear effect ( $\mathrm{p}<0.05$; Table 3$)$ present except for the neck weight, which

Table 2. Carcass characteristics from lambs fed diet with palm kernel cake

\begin{tabular}{|c|c|c|c|c|c|c|c|c|}
\hline \multirow{2}{*}{ Item } & \multicolumn{5}{|c|}{ Proportion of kernel cake (\% DM) } & \multirow{2}{*}{ SEM } & \multicolumn{2}{|c|}{ p-value } \\
\hline & 0 & 7.5 & 15 & 22.5 & 30 & & $\mathbf{L}$ & Q \\
\hline EBW $(\mathrm{kg})^{1)}$ & 25.17 & 25.87 & 23.76 & 22.12 & 20.84 & 0.295 & $<0.001$ & 0.403 \\
\hline $\mathrm{HCW}(\mathrm{kg})^{2)}$ & 14.06 & 14.11 & 12.96 & 11.97 & 11.38 & 0.110 & $<0.001$ & 0.515 \\
\hline $\operatorname{CCW}(\mathrm{kg})^{3)}$ & 13.21 & 13.74 & 12.59 & 11.60 & 10.81 & 0.109 & $<0.001$ & 0.034 \\
\hline $\operatorname{HCY}(\%)^{4)}$ & 45.51 & 44.77 & 42.75 & 42.09 & 41.30 & 0.361 & $<0.001$ & 0.657 \\
\hline $\operatorname{CCY}(\%)^{5)}$ & 42.77 & 43.59 & 41.56 & 40.78 & 39.20 & 0.344 & $<0.001$ & 0.550 \\
\hline $\operatorname{RFT}(m m)^{6}$ & 2.50 & 2.33 & 1.67 & 2.11 & 1.81 & 0.095 & 0.037 & 0.258 \\
\hline $\mathrm{LMA}\left(\mathrm{cm}^{2}\right)$ & 13.73 & 15.16 & 12.44 & 14.02 & 12.38 & 0.344 & 0.250 & 0.630 \\
\hline
\end{tabular}

DM, dry matter; SEM, standard error of the mean; L, linear effects; Q, quadratic effects; EBW, empty body weight; HCW, hot carcass weight; CCW, cold carcass weight; HCY, hot carcass yield; CCY, cold carcass yield; RFT, rib fat thickness; LMA, longissimus muscle area.

1) $Y=26.19-0.165 x\left(r^{2}=0.67\right) .{ }^{2} Y=14.39-0.099 x\left(r^{2}=0.83\right) .{ }^{3)} Y=3.78-0.099\left(r^{2}=0.82\right) .{ }^{4)} Y=45.50-0.148 x\left(r^{2}=0.33\right)$.

${ }^{5)} Y=43.57-0.132 \times\left(r^{2}=0.34\right) .{ }^{6)} Y=2.40-0.021 \times\left(r^{2}=0.25\right)$. 
presented with a quadratic effect, where the inclusion of $7 \%$ of palm kernel cake provided the greatest neck weight and the lowest weight was observed with $30 \%$ of inclusion. However, there was no difference $(\mathrm{p}>0.05)$ for cut yield as a function of the levels of inclusion of palm kernel cake.

The weight of the heart, liver, kidney fat, perirenal fat, small and large intestine, and gastrointestinal tract decreased as a function of the inclusion of palm kernel cake in the diet $(\mathrm{p}<0.05$; Table 4). Nevertheless, the gastrointestinal content was greater for animals that were fed increasing levels of cake. It was estimated $5,683.33$ and 6,656.03 $\mathrm{g}$ for 0 and $30 \%$ of inclusion of palm kernel cake, respectively. For the other organs and viscera, differences were not verified ( $\mathrm{p}>0.05$; Table 4$)$.

The sarcomere length of animals that received palm kernel cake decreased linearly ( $\mathrm{p}<0.05$; Table 5$)$. An effect was not observed ( $p>0.05$; Table 5 ) for the other variables related to meat quality as palm kernel cake was added to the diet. It is worth noting that the red staining intensity, indicated as $\mathrm{A}$, had a tendency to decrease $(\mathrm{p}=0.050)$.

\section{DISCUSSION}

The characteristics related to carcass weight and yield (Table 2) decreased as corn and soybean meal were replaced with palm kernel cake. This can be explained by the reduction in the empty body gain, because the changes that are necessary to replace the energy and protein ingredients of feedstuffs with a high neutral detergent fiber (NDF) content, such as palm kernel cake, can

Table 3. Commercial cut weight and yield of lambs fed diet with palm kernel cake

\begin{tabular}{|c|c|c|c|c|c|c|c|c|}
\hline \multirow{2}{*}{ Item } & \multicolumn{5}{|c|}{ Proportion of kernel cake (\% DM) } & \multirow{2}{*}{ SEM } & \multicolumn{2}{|c|}{$\mathrm{p}$-value } \\
\hline & 0 & 7.5 & 15 & 22.5 & 30 & & $\mathbf{L}$ & Q \\
\hline \multicolumn{9}{|c|}{ Commercial cuts $(\mathrm{kg})$} \\
\hline Neck ${ }^{1)}$ & 1.32 & 1.40 & 1.32 & 1.13 & 1.00 & 22.77 & $<0.001$ & 0.0345 \\
\hline Shoulder ${ }^{2)}$ & 2.50 & 2.65 & 2.45 & 2.28 & 2.14 & 31.03 & 0.002 & 0.0893 \\
\hline $\mathrm{Rib}^{3)}$ & 3.34 & 3.43 & 3.12 & 2.74 & 2.60 & 49.07 & 0.001 & 0.332 \\
\hline Loin $^{4)}$ & 0.994 & 0.979 & 0.910 & 0.877 & 0.838 & 16.19 & 0.003 & 0.894 \\
\hline Leg $^{5)}$ & 4.26 & 4.43 & 4.04 & 3.91 & 3.62 & 44.30 & $<0.001$ & 0.119 \\
\hline Flank steak ${ }^{6)}$ & 7.94 & 7.39 & 7.44 & 6.54 & 5.62 & 17.38 & 0.002 & 0.334 \\
\hline \multicolumn{9}{|c|}{ Commercial cut yield (\%) } \\
\hline Neck & 10.02 & 10.17 & 10.53 & 9.75 & 9.60 & 0.147 & 0.202 & 0.155 \\
\hline Shoulder & 18.98 & 19.31 & 19.40 & 19.58 & 19.82 & 0.207 & 0.201 & 0.958 \\
\hline Rib & 25.14 & 24.94 & 24.84 & 23.76 & 24.07 & 0.73 & 0.182 & 0.492 \\
\hline Loin & 7.53 & 7.13 & 7.24 & 7.58 & 7.74 & 0.107 & 0.334 & 0.160 \\
\hline Leg & 32.34 & 33.07 & 32.08 & 33.66 & 33.57 & 0.253 & 0.080 & 0.645 \\
\hline Flank steak & 5.99 & 5.38 & 5.91 & 5.67 & 5.20 & 0.126 & 0.143 & 0.626 \\
\hline
\end{tabular}

DM, dry matter; SEM, standard error of the mean; L, linear effects; $Q$, quadratic effects.

1) $Y=1,341+6.6 x-0.5 x^{2}\left(r^{2}=0.55\right) .{ }^{2)} Y=2,618-14.4 x\left(r^{2}=0.65\right) .{ }^{3)} Y=3.48-0.028 x(r 2=0.34) .{ }^{4)} Y=1,002-5.5 x\left(r^{2}=0.42\right)$.

${ }^{5)} Y=4,459-25 x\left(r^{2}=0.74\right) .{ }^{6} Y=808-7.3 x\left(r^{2}=0.45\right)$.

Table 4. Non-carcass components of lambs fed diet with palm kernel cake

\begin{tabular}{|c|c|c|c|c|c|c|c|c|}
\hline \multirow{2}{*}{ Item } & \multicolumn{5}{|c|}{ Proportion of kernel cake (\% DM) } & \multirow{2}{*}{ SEM } & \multicolumn{2}{|c|}{ p-value } \\
\hline & 0 & 7.5 & 15 & 22.5 & 30 & & $\mathrm{~L}$ & Q \\
\hline Heart $^{1)}$ & 132.8 & 125.0 & 120.6 & 98.3 & 106.7 & 0.71 & 0.017 & 0.088 \\
\hline Liver $^{2)}$ & 434.4 & 431.7 & 427.2 & 367.2 & 346.7 & 8.58 & 0.002 & 0.307 \\
\hline Kidney & 79.4 & 103.3 & 146.7 & 67.8 & 138.9 & 1.97 & 0.486 & 0.904 \\
\hline Pancreas & 42.2 & 42.2 & 38.9 & 42.2 & 40.0 & 1.60 & 0.821 & 0.814 \\
\hline Perirenal fat ${ }^{3)}$ & 433.9 & 378.8 & 362.8 & 264.4 & 231.1 & 18.71 & 0.001 & 0.884 \\
\hline Rumen-reticulum & 699.4 & 704.4 & 753.3 & 721.7 & 672.8 & 10.05 & 0.055 & 0.094 \\
\hline Omasum & 74.4 & 76.1 & 83.9 & 72.8 & 76.1 & 1.72 & 0.385 & 0.639 \\
\hline Abomasum & 140.6 & 121.1 & 129.4 & 120.0 & 125.6 & 4.11 & 0.455 & 0.291 \\
\hline Small intestine ${ }^{4)}$ & 495.0 & 485.6 & 419.4 & 377.8 & 411.1 & 10.62 & 0.003 & 0.149 \\
\hline Large intestine $^{5)}$ & 339.4 & 318.3 & 338.1 & 259.4 & 272.2 & 8.20 & 0.004 & 0.748 \\
\hline Postruminal tract empty & $1,748.9$ & 1,705.6 & $1,724.2$ & $1,551.7$ & $1,557.8$ & 24.39 & 0.021 & 0.871 \\
\hline Content gastrointestinal tract ${ }^{7)}$ & $5,683.9$ & $5,686.1$ & $5,811.3$ & $6,542.2$ & $6,686.2$ & 214.51 & 0.039 & 0.543 \\
\hline
\end{tabular}

DM, dry matter; SEM, standard error of the mean; $L$, linear effects; $Q$, quadratic effects.

1) $Y=141.11-6.22 x\left(r^{2}=0.09\right) .{ }^{2} Y=449.4-3.2 x\left(r^{2}=0.20\right) .{ }^{3)} Y=438.51-6.94 x\left(r^{2}=0.26\right) .{ }^{4)} Y=492.89-3.67 x\left(r^{2}=0.18\right)$.

${ }^{5)} Y=344.18-2.58 \times\left(r^{2}=0.18\right) .{ }^{6} Y=1,764.84-7.15 \times\left(r^{2}=0.12\right) .{ }^{7)} Y=5,513.33+38.09 \times\left(r^{2}=0.17\right)$. 
Table 5. Meat quality of lambs fed diet with palm kernel cake

\begin{tabular}{|c|c|c|c|c|c|c|c|c|}
\hline \multirow{2}{*}{ Item } & \multicolumn{5}{|c|}{ Proportion of kernel cake (\% DM) } & \multirow{2}{*}{ SEM } & \multicolumn{2}{|c|}{$\mathrm{p}$-value } \\
\hline & 0 & 7.5 & 15 & 22.5 & 30 & & L & Q \\
\hline WBSF (N) & 2.05 & 1.81 & 1.57 & 2.06 & 1.99 & 0.113 & 0.880 & 0.24 \\
\hline Sarcomere length" & 1.84 & 1.87 & 1.65 & 1.74 & 1.43 & 0.047 & 0.009 & 0.36 \\
\hline Total loss (\%) & 35.63 & 34.53 & 34.49 & 32.43 & 37.91 & 0.695 & 0.670 & 0.07 \\
\hline Total collagen (mg/g) & 0.05 & 0.05 & 0.08 & 0.06 & 0.08 & 0.003 & 0.108 & 0.79 \\
\hline Collagen solubility (\%) & 62.19 & 54.14 & 57.94 & 45.46 & 55.97 & 1.426 & 0.220 & 0.35 \\
\hline \multicolumn{9}{|l|}{ Color } \\
\hline$L^{* 2)}$ & 39.58 & 39.09 & 41.16 & 39.45 & 40.16 & 0.356 & 0.550 & 0.64 \\
\hline$a^{* 21}$ & 13.34 & 13.99 & 12.52 & 12.83 & 11.63 & 0.310 & 0.050 & 0.47 \\
\hline$b^{\star 2)}$ & 13.52 & 14.17 & 14.50 & 14.34 & 13.96 & 0.200 & 0.430 & 0.14 \\
\hline
\end{tabular}

DM, dry matter; SEM, standard error of the mean; L, linear effects; Q, quadratic effects; WBSF, Warner-Bratzler shear force.

1) $Y=1.89-0.012 x\left(r^{2}=0.16\right) .{ }^{2)} L^{*}$, lightness; $a^{*}$, redness; $b^{*}$, yellowness.

modify the passage rate of the diet, which will affect the intake of the animals. Despite the fact that NDF is the main energy source for animals that are raised in tropical pastures, the indigestible portion occupies space in the gastrointestinal tract due to its physical and chemical properties, which favor the rumen filling effect [16].

NDF from tropical feedstuffs is characterized by highly heterogeneous degradation, which is responsible for significant changes in the rumen-reticulum because first, it influences potentially digestible NDF, which provides energy to animals by breaking down fiber carbohydrates and second, it affects the indigestible portion of NDF that is not able to be utilized by ruminal microorganisms. Therefore, its passage in the gastrointestinal slows the feed intake rate, thereby negatively affecting the carcass development and weight of the animal [17]. This hypothesis can be confirmed by evaluating the results of subcutaneous fat thickness, which decreases as a function of the level of palm kernel cake, as evidenced by the changes in body tissue deposition when the highly degradable energy source was replaced by a slow digestion source [18].

The weight of commercial cuts followed the trend that was observed for other quantitative carcass characteristics in that they decreased linearly (Table 3 ). It can be verified that independent of the anatomic location of the cut in the animal, even very early cuts during the slaughterhouse finishing such as the leg and pallet decreased in weight as a function of the diet, which made it more evident that nutritional components influence the performance of the animals [19]. Nevertheless, the percentage of cuts was not altered, which justifies the well-balanced distribution of muscle and fat in the body of animals since commercial cuts represent the tissue distribution in different regions of the carcass [5].

It is known that internal organs that are metabolically active such as the liver, heart, kidneys, and gastrointestinal tract, in spite of representing less than $10 \%$ of the body weight of animals, represent almost $50 \%$ of the energy that is spent under normal feeding conditions [20]. The animals can be gain body weight even during times of feed restriction; this can occur in situations when body weight gain does not represent the genetic potential of animals, as evidenced by this study when high energy-value feedstuffs such as corn and soybean meal were replaced with palm kernel cake, which altered the nutrient availability while reducing the body weight gain of the animals [21]. This is while considering that the inclusion of palm kernel cake in the diet caused a certain degree of feed restriction. Therefore, the weight of the main metabolic organs such as the liver, heart, and small and large intestine were lower, followed by a reduction in the kidney fat $(\mathrm{p}<0.05$; Table 4$)$. However, a difference was not verified for the weights of the rumen-reticulum, omasum, and abomasum, possibly due to the chemical composition of palm kernel cake, which was added as a replacement for concentrate to increase the NDF contents of the diet by $30 \%$ (Table 1 ) and possibly, its indigestible portion caused an effect of rumen fill.

When the animals were fed diets with high indigestible fiber contents, the mechanism of feed compensation was utilized to supply the demand for energy by increasing the voluntary intake up to certain physiological limits, although, this actually reduced the feed intake due to the effect of physical rumen fill [22]. This compensation process causes distension of the pre-stomach walls, thereby increasing their volume capacity. This effect was observed in this study because in spite of the observed differences in the weights of the pre-stomachs, the gastrointestinal tract was heavier for animals that were fed diets with high levels of palm kernel cake $(\mathrm{p}<0.05$; Table 4$)$.

Sarcomere length was the unique variable related to the qualitative meat characteristics that differed among animals that received palm kernel cake in the diet $(\mathrm{p}<0.05$; Table 5$)$; lower means were observed as a function of increasing levels of palm kernel cake. The possible explanation for this effect might be due to two assumptions: the size of cuts was smaller for animals that were fed palm kernel cake-based diets, which supports the lower sarcomere length that was measured in the rib, and second, the shortening of muscle fibers during the cooling process of the carcass was affected by the subcutaneous fat thickness, which was lower for animals that were fed palm kernel cake-based diets 
(Table 2), thereby providing less muscle fiber isolation against the cold [23]. Despite the greater levels of ether extract when palm kernel cake was added, the dry matter intake decreased linearly [24], thus causing lower levels of adipose tissue deposition in the bodies of the animals.

The shortening of muscle cells due to the cold is irreversible because it leads to permanent contraction of the muscle and hardness of the meat [25]. However, in this study, the reduction in sarcomere length was not enough to alter the shear force that was applied to make the steak cut (Table 5). Despite the possibility of sarcomere shortening resulting in hardness of the meat, it was not positively correlated to shear force, but other factors such as the decreasing temperature and $\mathrm{pH}$ until the point of rigor mortis can significantly influence the level of firmness [26].

Other variables that can help to explain the lack of effect on shear force among animals is the percentage of soluble and insoluble collagen (Table 5), which did not vary among diets. The contribution of connective tissue (collagen), which is responsible for the degree of hardness, is muscle dependent. In addition, different muscles in the body have different amounts of connective tissue; for example, the Longissumus dorsi muscle has a relatively small amount of connective tissue, which explains the low correlation between shear force and the percentage of insoluble collagen [27].

Among the organoleptic characteristics of meat, coloration is the most important at the moment of acquisition for consumers, because differences in coloration influence the degree of acceptance of the product. Thus, animals that are slaughtered at similar ages and who are submitted to the same slaughter handling do not tend to present with differences in coloration of the muscle, except if there was an ingredient in the diet that can alter this characteristic; this was not observed in this study, since even though there was a scarce amount of subcutaneous fat (Table 2), the degree of yellow intensity did not differ among animals (Table 5).

\section{IMPLICATIONS}

The inclusion of palm kernel cake up to $30 \%$ in the diet does not cause changes in meat quality characteristics except for sarcomere length. However, quantitative carcass characteristics decrease with the use of palm kernel cake.

\section{CONFLICT OF INTEREST}

We certify that there is no conflict of interest with any financial organization regarding the material discussed in the manuscript.

\section{ACKNOWLEDGMENTS}

We would like to thank the CNPq and FAPESPA for their financial support.

\section{REFERENCES}

1.Costa RG, Medeiros GR, Duarte TF, et al. Salted goat and lamb meat: Typical regional product of the city of Petrolina, state of Pernambuco. Small Rumin Res 2011;98:51-4.

2.Ricardo HA, Fernandes ARM, Mendes LCN, et al. Carcass traits and meat quality differences between a traditional and an intensive production model of market lambs in Brazil: Preliminary investigation. Small Rumin Res 2015;130:141-5.

3.Badee G, Hidaka S. Growth performance, carcass characteristics, fatty acid composition and CLA concentrations of lambs fed diets supplemented with different oil sources. Animal Sci J 2014;85:118-26.

4.Cui J, Chong B, Rutherfurd SM, et al. Gross and true ileal digestible amino acid contents of several animal body proteins and their hydrolysates. Meat Sci 2013;94:349-54.

5.Lage JF, Paulino PVR, Pereira LGR, et al. Carcass characteristics of feedlot lambs fed crude glycerin contaminated with high concentrations of crude fat. Meat Sci 2014;96:108-13.

6.Valadares Filho SC, Machado PAS, Furtado T, Chizzotti ML, Amaral HF. Tabelas brasileiras de composição de alimentos para ruminantes. Viçosa, MG, Brazil: Editora UFV; 2015.

7.Bringel LML, Neiva JNM, Araújo VL, et al. Voluntary intake, apparent digestibility and nitrogen balance in sheep fed with palm kernel cake replacing elephant grass silage. R Bras Zootec 2011;40:1975-83.

8.Maciel RP, Neiva JNM, Araujo VL, et al. Intake, nutrient digestibility and performance of dairy heifers fed diets containing palm kernal cake. R Bras Zootec 2012;41:698-706.

9.Abubakr AR, Alimon AR, Yaakub H, Abdullah N, Ivan M. Growth, nitrogen metabolism and carcass composition of goats fed palm oil by-products. Small Rumin Res 2013;112:91-6.

10. Committee on Nutrient Requirements of Small Ruminants, National Research Council. Nutrient requirements of small ruminants. Washington, DC: National Academy Press; 2007.

11. Brasil - Ministério da agricultura. Pecuária e Abastecimento. Regulamento da inspeção industrial e sanitária de produtos de origem animal food of animal origin sanitary and industry inspection. Brasília: Ministério da Agricultura, Pecuária e Abastecimento; 1997.

12. Greiner SP, Rouse GH, Wilson DE, Cundiff LV, Wheeler TL. Accuracy of predicting weight and percentage of beef carcass retail product using ultrasound and live animal measures. J Anim Sci 2003;81:466-73.

13. AMSA, American Meat Science Association. Research guidelines for cookery, sensory evaluation and tenderness measurements of fresh meat. Chicago, IL: National Livestock and Meat Board; 1995.

14. Cross HR, West RL, Dutson TR. Comparison of methods for measuring sarcomere length in beef semitendinosus muscle. Meat Sci 1981;5:261-6.

15. Houben JH, van Dijk A, Eikelenboom G, Hoving-Bolink AH. Effect of dietary vitamin E supplementation, fat level and packaging on colour stability and lipid oxidation in minced beef. Meat Sci 2000;55: $331-6$.

16. Souza MA, Detmann E, Paulino MF, et al. Intake, digestibility, and rumen dynamics of neutral detergent fibre in cattle fed low-quality 
tropical forage and supplemented with nitrogen and/or starch. Trop Anim Health Prod 2010;42:1299-310.

17. Detmann E, Gionbelli MP, Huhtanen P. A meta-analytical evaluation of the regulation of voluntary intake in cattle fed tropical forage-based diets. J Anim Sci 2014;92:4632-41.

18. Costa MRGF, Pereira ES, Silva AMA, et al. Body composition and net energy and protein requirements of Morada Nova lambs. Small Rumin Res 2013;114:206-13.

19. Anderson F, Williams A, Pannier L, Pethick DW, Gardner GE. Sire carcass breeding values affect body composition in lambs. 1 . Effects on lean weight and its distribution within the carcass as measured by computed tomography. Meat Sci 2015;108:145-54.

20. Hersom MJ, Horn GW, Krehbiel CR, Phillips WA. Effect of live weight gain of steers during winter grazing: I. Feedlot performance, carcass characteristics, and body composition of beef steers. J Anim Sci 2004; 82:262-72.

21. Rotta PP, Valadres Filho SC, Gionbelli TR, et al. Effects of day of gestation and feeding regimen in Holstein $\times$ Gyr cows: II. Maternal and fetal visceral organ mass. J Dairy Sci 2015;98:3211-23.

22. Whetsell MS, Prigge EC, Nestor EL. Influence of mass of ruminal contents on voluntary intake and digesta passage in steers fed a forage and a concentrate diet. J Anim Sci 2004;82:1806-17.

23. Warner RD, Jacob RH, Hocking Edwards JE, et al. Quality of lamb meat from the information nucleus flock. Anim Prod Sci 2010;50: 1123-34.

24. Santos RC, Alves KS, Mezzomo R, et al. Performance of feedlot lambs fed palm kernel cake-based diets. Trop Anim Health Prod 2016;48: 367-72.

25. White A, O’Sullivan A, O’Neill EE, Troy DJ. Manipulation of the prerigor phase to investigate the significance of proteolysis and sarcomere length in determining the tenderness of bovine $M$. longissimus dorsi. Meat Sci 2006;73:204-8.

26. Hopkins DL, Toohey ES, Lamb TA, et al. Explaining the variation in the shear force of lamb meat using sarcomere length, the rate of rigor onset and pH. Meat Sci 2011;88:794-6.

27. Starkey CP, Geesink GH, Oddy VH, Hopkins DL. Explaining the variation in lamb longissimus shear force across and within ageing periods using protein degradation, sarcomere length and collagen characteristics. Meat Sci 2015;105:32-7. 